Cite this: CrystEngComm, 2013, 15, 7285

Received 10th April 2013,

Accepted 3rd July 2013

DOI: $10.1039 /$ c3ce40619a

www.rsc.org/crystengcomm

\title{
Primary nucleation of salicylamide: the influence of process conditions and solvent on the metastable zone width
}

\author{
Fredrik L. Nordström, ${ }^{a}$ Michael Svärd ${ }^{b}$ and Åke C. Rasmuson*bc
}

\begin{abstract}
The onset of nucleation of salicylamide in organic solvents has been measured for a total of 2911 nucleation experiments at a constant cooling rate. The experiments are divided into series of different experimental conditions and for each series, the mean values and distributions of the nucleation events have been recorded. Generally, a significant spread in the onset of nucleation among identical repeated experiments was observed. The solvent and the cooling rate were found to be the factors exerting the greatest influence on the onset of nucleation, whereas the expected effects of the solution volume and the saturation temperature were largely absent. A correlation is observed between the supersaturation ratio at the average onset of nucleation and a group of parameters extracted from the pre-exponential factor in the classical nucleation rate equation, which is in agreement with the concept that a higher attachment frequency facilitates nucleation. It is also found that there can be a profound difference in the metastable zone width between experiments in open and closed crystallizers.
\end{abstract}

\section{Introduction}

An undersaturated solution that is being cooled down will typically start to crystallize at a certain temperature below the saturation temperature of the solute. This gap between the point of saturation of a solution and the onset of crystallization is usually referred to as the metastable zone width, MZW. Unlike the solubility, the MZW is not a thermodynamically defined property, but rather describes from a practical point of view the maximum level of supersaturation that can be operated in a process without having uncontrolled nucleation. It is also commonly interpreted as the maximum level of supersaturation where primary nucleation will not dominate the process, even though the distinction between primary and secondary nucleation is not always clear-cut. Some properties of the crystals obtained from a crystallization process are directly related to the MZW; a narrower metastable zone typically leads to an increase in the size of the particles and reduces the risk of obtaining unwanted solid phases, such as metastable polymorphs or solvates. However, from an industrial point of view, an overly narrow MZW may cause problems if a sudden temperature drop occurs in the process, e.g. as a result of transferring warm solutions between different reactors, or when performing polishing filtration

\footnotetext{
${ }^{a}$ AbbVie, North Chicago, IL, USA

${ }^{b}$ Department of Chemical Engineering and Technology, KTH Royal Institute of Technology, Stockholm, Sweden. E-mail: rasmuson@ket.kth.se; Tel: +46-8-790 8227 ${ }^{c}$ Department of Chemical and Environmental Science, Solid State Pharmaceutical Cluster, Materials and Surface Science Institute, University of Limerick, Ireland
}

operations. It also limits the option of utilizing seeded crystallization to control particle and bulk properties. On the other hand, a large MZW may lead to a rapid precipitation process, causing suboptimal impurity rejection, inclusion issues, poor filterability and potential difficulties in downstream operations, if not avoided by the introduction of seeds. In the pharmaceutical industry, controlling the crystal properties is essential for, in particular, the synthesis step involving the final active pharmaceutical ingredient, and a knowledge of the MZW is therefore of considerable importance and interest.

The MZW depends primarily on the rate of nucleation, but may also be affected by the growth rate. It can vary significantly between different solute-solvent systems, and thus is difficult to predict. The MZW is known to be affected by a multitude of factors, among which are hydrodynamic conditions such as agitation rate, solution volume, reactor and impeller characteristics and dimensions, operating conditions such as the cooling rate and temperature, as well as other factors like solution impurities, the presence of particulates, the solution history ${ }^{1}$ and ultrasound. ${ }^{2}$ The design of a crystallization process may therefore require a relatively extensive amount of experimentation to achieve desired particle properties, and the scale-up is not trivial.

Primary nucleation is generally regarded as a stochastic phenomenon related to the random behaviour of molecules in solution, which prior to growing into visible crystals form subcritical clusters. Despite the unpredictable arrangement of solute molecules forming ordered structures, few studies report of the variance in the MZW determined under 
reproducible experimental conditions. As pointed out by Izmailov et al. (1999), ${ }^{3}$ the stochastic nature of primary nucleation can only be captured by a great number of experiments and hence it is imperative that the nucleation experiments are repeated.

In the present paper, some of the factors expected to influence the MZW have been investigated: the saturation temperature, the solvent, the cooling rate and the solution volume. The difference when crystallization takes place in an open as opposed to a closed crystallizer has also been explored. The variance in the MZW has been quantified for each set of conditions by repeating experiments up to 200 times. The organic compound salicylamide was selected to rule out any effect of polymorphism, as it has only been found to crystallize as one solid form. ${ }^{4,5}$ To the best of our knowledge, no data on the primary nucleation of salicylamide has been reported previously.

\section{Theory}

In a metastable zone width experiment, as illustrated in Fig. 1, a solution is cooled down from a saturated state represented by point $1\left(T_{1}, x_{1}, \gamma_{1}\right)$, until nucleation takes place in the supersaturated solution at some point $2\left(T_{2}=T_{3}, x_{2}=x_{1}, \gamma_{2}\right)$. The MZW is traditionally quantified as an undercooling temperature difference, $\Delta T$ :

$$
\Delta T=T_{1}-T_{3}
$$

The thermodynamic driving force for nucleation is the difference in chemical potential between the solute in the supersaturated solution, $\mu$ (at point 2) and the solute as a pure solid, the latter being equal to that of the solute in a saturated solution, $\mu_{\mathrm{eq}}$ (at point 3). The driving force can be expressed in terms of activities, $a$, and mole fraction concentrations, $x$, as:

$$
\Delta \mu=\mu-\mu_{\mathrm{eq}}=R T \ln \left[\frac{a}{a_{\mathrm{eq}}}\right]=R T \ln \left[\frac{x}{x_{\mathrm{eq}}} \frac{\gamma}{\gamma_{\mathrm{eq}}}\right] \cong R T \ln \left[\frac{x}{x_{\mathrm{eq}}}\right]=R T \ln S
$$

Commonly the ratio of activity coefficients is assumed to be close to unity, but this can only be justified when the influence

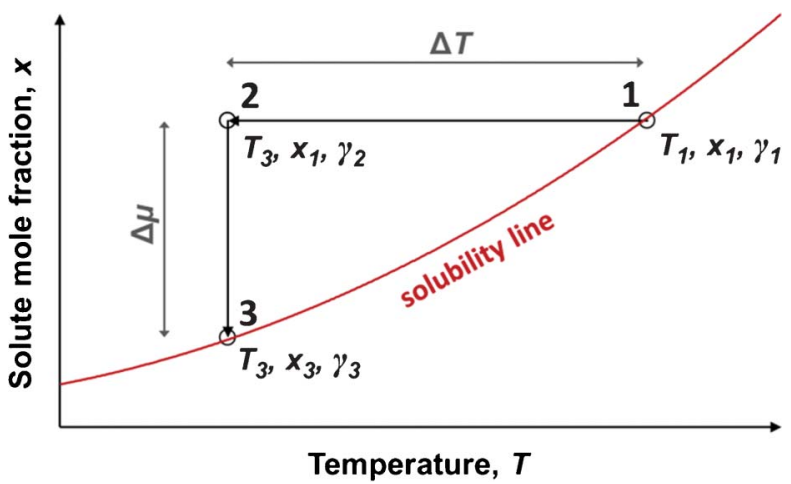

Fig. 1 A schematic illustration of the metastable zone width. of the concentration on $\gamma$ is negligible, when the solution is ideal (i.e. $\gamma$ is unity) or when $x \approx x_{\text {eq }}$. In many cases of crystallization of organic compounds this assumption appears questionable, adopted primarily for reasons of convenience.

The metastable zone width is often used as a measure of the nucleation kinetics, ${ }^{6,7}$ which assumes that the time of growth of nuclei to experimental detection can be neglected. In the classical theory of homogeneous primary nucleation (CNT), the steady-state rate of nucleation, $J$, defined as the number of nuclei born in unit volume per unit time, can be written as: ${ }^{8,9}$

$$
J=f^{*} C^{*} Z
$$

where $f^{*}$ is the frequency of attachment of molecules to a critical nucleus, $C^{*}$ is the equilibrium concentration of critical nuclei and $Z$ is a correction factor to account for deviation from the equilibrium state. In other words, the nucleation rate is the product of the concentration of critical nuclei in the solution $\left(C^{*} Z\right)$ and the rate at which molecules are added to such a critical nucleus making its size large enough that further growth is thermodynamically favourable. Assuming spherical nuclei and monomer attachment governed by volume diffusion, the attachment frequency in solution is given by: ${ }^{8}$

$$
f^{*}=4 \pi r^{*} \kappa C D
$$

where $\kappa$ is a coefficient ${ }^{10}$ accounting for the fraction of successful collisions (between 0 and 1), $C$ is the concentration, $D$ is the diffusivity, and $r^{*}$ is the critical radius which through the Thomson-Gibbs equation can be written as:

$$
r^{*}=\frac{2 \sigma V_{\mathrm{m}}}{\Delta \mu}
$$

where $V_{\mathrm{m}}$ is the molecular volume of the solute and $\sigma$ is the cluster-solution interfacial free energy. $C^{*}$ can be written as:

$$
C^{*}=C_{\mathrm{ns}} \exp \left(-\frac{\Delta G^{*}}{k T}\right)
$$

where $k$ is the Boltzmann constant, $T$ is the absolute temperature, $C_{\mathrm{ns}}$ is the concentration of nucleation sites, which for homogeneous nucleation are all single molecules, ${ }^{8}$ and $\Delta G^{*}$ is the height of the free energy barrier that must be surpassed in order for primary nucleation to occur. For spherical nuclei:

$$
\Delta G^{*}=\frac{16 \pi}{3} \frac{\sigma^{3} V_{\mathrm{m}}^{2}}{\Delta \mu^{2}}
$$

The critical free energy required to form a stable nucleus thus only depends on the thermodynamic driving force, the solute molecular volume and the interfacial energy.

$Z$ is given by: ${ }^{8}$

$$
Z=\frac{\Delta \mu^{2}}{8 \pi V_{\mathrm{m}}} \sqrt{\frac{1}{k T \sigma^{3}}}
$$


Inserting eqn (4)-(8) into eqn (3) leads to:

$$
J=\kappa C C_{\mathrm{ns}} D \Delta \mu \sqrt{\frac{1}{k T \sigma}} \exp \left(-\frac{16 \pi}{3 k T} \frac{\sigma^{3} V_{\mathrm{m}}^{2}}{\Delta \mu^{2}}\right)
$$

All three factors in eqn (3) depend quite strongly on the supersaturation. On increasing the driving force, the number of critical nuclei and the Zeldovich factor strongly increase but the attachment frequency decreases. Furthermore in a metastable zone width cooling experiment, all three factors have a strong temperature dependence embedded in the driving force temperature dependence, although this partly cancels out in the overall expression. The influence of the solvent is mainly manifested through the interfacial energy which appears in all three factors. This parameter, which is best viewed as an excess free energy resulting from the unbalanced intermolecular forces of the molecules at the nucleus surface, is known to be difficult to determine experimentally despite being the subject of a significant number of studies. ${ }^{11,12}$ Moreover, the interfacial energy normally varies between the different faces of a crystal and it may not be justifiable to assume that the interfacial energy of a nucleus of near-critical radius is equal to the interfacial energy of macroscopic crystals.

Apart from the interfacial energy, the solvent is expected to influence the pre-exponential part of eqn (9) (often denoted $J_{0}$ ) through the mobility of molecules in solution, and the likelihood of a solute molecule attaching itself to a cluster. Making the comparison with molecular diffusivity in solution, the rate of transport of molecules should be inversely proportional to the solution viscosity, and proportional to the square root of the solvent molecular weight. Accordingly we would expect that the rate of nucleation besides the influence of the interfacial energy also exhibits a dependence such as:

$$
J_{0} \propto \frac{C \sqrt{M}}{\eta}
$$

Aside from the solvent, concentration and temperature, several other experimental factors are known to affect the MZW, some of which can be introduced into the CNT through the pre-exponential factor by different models. ${ }^{8,9,13,14}$

It needs to be recognized that for experiments in general, such as those reported herein, nucleation will most likely be catalysed by e.g. surfaces of the equipment and dust particles, for which the term heterogeneous primary nucleation is used. The catalysing effect leads to a lowering of the interfacial energy, which is normally accounted for by introducing a correction factor in eqn (7), and occasionally by using the term 'effective interfacial energy'. In addition, $C_{\mathrm{ns}}$, the concentration of nucleation sites appearing in eqn (6), takes on a lower value, which is usually assumed to explain why experimentally determined pre-exponential factors are much lower than theoretical estimates. However, the equations for heterogeneous nucleation exhibit the same basic functional form as for the homogeneous case. Furthermore, the nucleation data reported in this work retains a significant stochastic nature as well as an influence of solvent and other process conditions, and this is the main focus of analysis.

\section{Experimental work}

In total 2911 primary nucleation experiments have been carried out for salicylamide dissolved in five different pure solvents. The experiments are organized in series of multiple repeat experiments carried out under identical experimental conditions. 2558 experiments have been carried out in sealed test tubes each containing approx. $15 \mathrm{ml}$ solution, 253 experiments have been carried out in sealed bottles containing 150 or $500 \mathrm{ml}$ of solution, and 100 experiments have been carried out in jacketed crystallizers containing $150 \mathrm{ml}$ of solution. For each solvent, the effects of different saturation temperatures (between $30-50{ }^{\circ} \mathrm{C}$ ) and cooling rates (between $5-20{ }^{\circ} \mathrm{C} \mathrm{h}^{-1}$ ) have been evaluated.

\section{Materials}

Salicylamide (CAS reg. no.: 65-45-2) was purchased from Sigma-Aldrich (purity 99\%) and used as obtained. The solvents methanol ( $\mathrm{MeOH}$, HiperSolv, purity $>99.8 \%$ ), acetonitrile (ACN, LiChrosolv, gradient grade, purity $>99.8 \%$ ), acetic acid (HAc, Pro Analysi, purity 96\%), acetone (HiperSolv, purity $>99.8 \%$ ) and ethyl acetate (EtOAc, HiperSolv, purity $>99.8 \%$ ) were purchased from VWR/Merck and used as obtained.

\section{Procedure}

Saturated solutions were prepared in $250 \mathrm{ml}$ bottles by dissolving salicylamide in each solvent. The bottles were sealed and the solutions equilibrated in the presence of excess solids for a minimum of four hours at constant temperature, while being agitated using magnetic stir bars. The saturated solutions were filtered at $0.2 \mu \mathrm{m}$ (PTFE) over to $20 \mathrm{ml}$ test tubes (solution volume of $15 \mathrm{ml}$ ), $250 \mathrm{ml}$ bottles (solution volume of $150 \mathrm{ml}$ ) or $500 \mathrm{ml}$ bottles (solution volume of 500 $\mathrm{ml}$ ) all made out of glass. PTFE magnetic stir bars with pivot rings were added to the test tubes (bar dimensions: $15 \times 8$ $\mathrm{mm}$ ) and to the bottles (bar dimensions: $35 \times 8 \mathrm{~mm}$ ). The test tubes and bottles were tightly capped to prevent solvent evaporation and contamination.

(i) The test tubes and bottles were placed in thermostatic water baths at $10{ }^{\circ} \mathrm{C}$ above the saturation temperature of the solutions, except for the acetone solutions saturated at $50{ }^{\circ} \mathrm{C}$ where only $5{ }^{\circ} \mathrm{C}$ superheating was used. The solutions in the test tubes and bottles were agitated at $300 \mathrm{rpm}$ using a multipole magnetic stirring plate (Variomag) for a minimum of three hours to delete any effect of solution memory. ${ }^{1}$

(ii) The test tubes and bottles were then transferred to a cryostat (Julabo, FP45-HP, accuracy $0.01{ }^{\circ} \mathrm{C}$ ) and agitated at $400 \mathrm{rpm}$. The water temperature in the cryostat corresponded to the saturation temperature of the solutions. A total of 14 test tubes or 4 bottles were placed simultaneously in the cryostat.

(iii) After $15 \mathrm{~min}$, the solutions in the test tubes or bottles in the cryostat were cooled at a constant cooling rate of 5, 10 or 


\begin{tabular}{|c|c|c|c|c|c|c|c|c|}
\hline \multirow[b]{2}{*}{ No. } & \multirow[b]{2}{*}{ Vessel type } & \multirow[b]{2}{*}{ Experiments } & \multicolumn{3}{|c|}{ Parameters } & \multicolumn{3}{|c|}{ MZW } \\
\hline & & & $T_{\text {eq }}\left[{ }^{\circ} \mathrm{C}\right]$ & $-\mathrm{d} T / \mathrm{d} t\left[{ }^{\circ} \mathrm{C} \mathrm{h}^{-1}\right]$ & $V_{\text {soln }}[\mathrm{ml}]$ & $\begin{array}{l}{[R T \ln S]_{\mathrm{avg}}(\mathrm{SD} ; \mathrm{SE})} \\
{\left[\mathrm{kJ} \mathrm{\textrm {mol } ^ { - 1 } ]}\right.}\end{array}$ & $S_{\text {avg }}(\mathrm{SD} ; \mathrm{SE})$ & $\Delta T_{\mathrm{avg}}(\mathrm{SD} ; \mathrm{SE})\left[{ }^{\circ} \mathrm{C}\right]$ \\
\hline A1 & Sealed test tube & 128 & 50 & 5 & 15 & $0.84(0.50 ; 0.044)$ & $1.42(0.31 ; 0.027)$ & $11.2(7.0 ; 0.62)$ \\
\hline $\mathrm{A} 2$ & Sealed test tube & 56 & 45 & 5 & 15 & $0.69(0.29 ; 0.039)$ & $1.32(0.16 ; 0.022)$ & $9.3(4.1 ; 0.55)$ \\
\hline A3 & Sealed test tube & 56 & 40 & 5 & 15 & $1.05(0.50 ; 0.067)$ & $1.57(0.35 ; 0.047)$ & $15(7.6 ; 1.02)$ \\
\hline A4 & Sealed test tube & 53 & 35 & 5 & 15 & $0.80(0.39 ; 0.054)$ & $1.41(0.26 ; 0.036)$ & $11.6(6.1 ; 0.83)$ \\
\hline A5 & Sealed test tube & 56 & 30 & 5 & 15 & $0.77(0.28 ; 0.038)$ & $1.38(0.18 ; 0.024)$ & $11.3(4.5 ; 0.59)$ \\
\hline A6 & Sealed test tube & 136 & 50 & 10 & 15 & $1.35(0.49 ; 0.042)$ & $1.75(0.33 ; 0.028)$ & $18.5(7.0 ; 0.60)$ \\
\hline A7 & Sealed test tube & 126 & 50 & 20 & 15 & $1.55(0.51 ; 0.046)$ & $1.90(0.39 ; 0.035)$ & $21.4(7.6 ; 0.68)$ \\
\hline A8 & Sealed $250 \mathrm{ml}$ bottle & 128 & 50 & 20 & 150 & $1.53(0.41 ; 0.037)$ & $1.87(0.33 ; 0.029)$ & $21.1(6.2 ; 0.55)$ \\
\hline A9 & Sealed $500 \mathrm{ml}$ bottle & 125 & 50 & 20 & 500 & $1.64(0.38 ; 0.067)$ & $1.96(0.32 ; 0.056)$ & $22.7(5.7 ; 0.51)$ \\
\hline A10 & Open crystallizer & 10 & 50 & 20 & 150 & $0.12(0.03 ; 0.011)$ & $1.047(0.01 ; 0.004)$ & $1.5(0.4 ; 0.14)$ \\
\hline A11 & Sealed crystallizer & 10 & 50 & 20 & 150 & $0.9(0.38 ; 0.122)$ & $1.43(0.23 ; 0.073)$ & $12(5.4 ; 1.70)$ \\
\hline
\end{tabular}

$20{ }^{\circ} \mathrm{C} \mathrm{h}^{-1}$ (verified in a separate experiment by placing a thermometer in the solution bulk) until nucleation was observed in all solutions. The onset of nucleation and the bath temperature shown on the cryostat display were recorded with a camcorder.

(iv) After crystallization was observed in the solutions, the test tubes or bottles were transferred back to the high temperature water bath, and the crystals were dissolved completely.

Steps (i)-(iv) were repeated up to 10 times. A total of at least 50 nucleation events were recorded for each set of experimental conditions. After the last cooling crystallization sequence, the crystals in the solutions were again dissolved completely and the concentration of the solutions determined gravimetrically. The experimental procedure of the gravimetric concentration measurements as well as the solubility of salicylamide in the aforementioned solvents have been reported previously. ${ }^{4}$ The temperature of the water bath and cryostat was validated by a calibration mercury thermometer (Thermo-Schneider, accuracy of $0.01{ }^{\circ} \mathrm{C}$ ).

In an additional set of experiments, the MZW of salicylamide was determined in jacketed glass crystallizers (Saveen Werner, $250 \mathrm{ml}$ ) connected to a cryostat. $150 \mathrm{ml}$ of saturated solution was filtered (pore size $=0.2 \mu \mathrm{m}$ ) and transferred to the crystallizer. The crystallizer was placed on top of a magnetic stirrer plate and the solution was agitated at $400 \mathrm{rpm}$ using a PTFE stir bar (bar dimensions: $35 \times 8 \mathrm{~mm}$ ). The same procedure as previously outlined was employed, except that in half of these experiments no crystallizer lid was fitted, leaving the solution exposed to the surrounding air. In the other half of experiments the crystallizer was completely sealed.

The experimental results were examined for non-random behaviour, e.g. between the different tubes and bottles, different mother liquor preparations, etc., but no such behaviour could be found. The onset of nucleation was observed as a rapid transformation from a transparent solution into a white suspension and the temperature at which crystals first appeared in the solution was determined visually with an estimated accuracy of $\pm 0.1{ }^{\circ} \mathrm{C}$. Initial preliminary experiments conducted when the solutions were undersaturated for only $10 \mathrm{~min}$ resulted in a systematic gradual decrease of the MZW during successive cooling crystallizations of the same set of solutions. This effect of solution history disappeared when the solutions were kept in an undersaturated state as described for at least one hour. In this study, all solutions were maintained undersaturated for at least three hours to ensure the deletion of any solution memory.

\section{Results and evaluation}

The results are given as series of repeat experiments carried out under identical conditions, in one table for each solvent

Table 2 Nucleation experiments in acetonitrile (717 experiments)

\begin{tabular}{|c|c|c|c|c|c|c|c|c|}
\hline \multirow[b]{2}{*}{ No. } & \multirow[b]{2}{*}{ Vessel type } & \multirow[b]{2}{*}{ Experiments } & \multicolumn{3}{|c|}{ Parameters } & \multicolumn{3}{|c|}{ MZW } \\
\hline & & & $T_{\text {eq }}\left[{ }^{\circ} \mathrm{C}\right]$ & $\begin{array}{l}-\mathrm{d} T / \mathrm{d} t \\
{\left[{ }^{\circ} \mathrm{C} \mathrm{h}^{-1}\right]}\end{array}$ & $V_{\text {soln }}[\mathrm{ml}]$ & $\begin{array}{l}{[R T \ln S]_{\mathrm{avg}}(\mathrm{SD} ; \mathrm{SE})} \\
{\left[\mathrm{kJ} \mathrm{mol}^{-1}\right]}\end{array}$ & $S_{\text {avg }}(\mathrm{SD} ; \mathrm{SE})$ & $\Delta T_{\text {avg }}(\mathrm{SD} ; \mathrm{SE})\left[{ }^{\circ} \mathrm{C}\right]$ \\
\hline B1 & Sealed test tube & 133 & 50 & 5 & 15 & $0.85(0.48 ; 0.042)$ & $1.42(0.28 ; 0.024)$ & $9.9(5.8 ; 0.50)$ \\
\hline B2 & Sealed test tube & 54 & 45 & 5 & 15 & $0.69(0.33 ; 0.045)$ & $1.32(0.19 ; 0.026)$ & $8.1(4.0 ; 0.54)$ \\
\hline B3 & Sealed test tube & 55 & 40 & 5 & 15 & $0.81(0.42 ; 0.056)$ & $1.41(0.27 ; 0.036)$ & 9.7 (5.1; 0.69) \\
\hline B4 & Sealed test tube & 56 & 35 & 5 & 15 & $0.74(0.42 ; 0.056)$ & $1.37(0.26 ; 0.035)$ & $8.9(5.2 ; 0.69)$ \\
\hline B5 & Sealed test tube & 56 & 30 & 5 & 15 & $0.58(0.29 ; 0.038)$ & $1.28(0.17 ; 0.023)$ & $7.0(3.6 ; 0.48)$ \\
\hline B6 & Sealed test tube & 205 & 50 & 10 & 15 & $1.23(0.57 ; 0.040)$ & $1.67(0.37 ; 0.026)$ & $14.5(6.9 ; 0.48)$ \\
\hline B7 & Sealed test tube & 138 & 50 & 20 & 15 & $1.20(0.56 ; 0.047)$ & $1.64(0.38 ; 0.032)$ & $14.2(6.8 ; 0.58)$ \\
\hline B8 & Open crystallizer & 10 & 50 & 20 & 150 & $0.21(0.04 ; 0.014)$ & $1.083(0.02 ; 0.006)$ & $2.4(0.5 ; 0.16)$ \\
\hline B9 & Sealed crystallizer & 10 & 50 & 20 & 150 & $0.79(0.27 ; 0.086)$ & $1.36(0.15 ; 0.047)$ & $9(3.2 ; 1.02)$ \\
\hline
\end{tabular}


Table 3 Nucleation experiments in acetic acid (396 experiments)

\begin{tabular}{|c|c|c|c|c|c|c|c|c|}
\hline \multirow[b]{2}{*}{ No. } & \multirow[b]{2}{*}{ Vessel type } & \multirow[b]{2}{*}{ Experiments } & \multicolumn{3}{|c|}{ Parameters } & \multicolumn{3}{|c|}{ MZW } \\
\hline & & & $T_{\text {eq }}\left[{ }^{\circ} \mathrm{C}\right]$ & $\begin{array}{l}-\mathrm{d} T / \mathrm{d} t \\
{\left[{ }^{\circ} \mathrm{C} \mathrm{h}^{-1}\right]}\end{array}$ & $V_{\text {soln }}[\mathrm{ml}]$ & $\begin{array}{l}{[R T \ln S]_{\mathrm{avg}}(\mathrm{SD} ; \mathrm{SE})} \\
{[\mathrm{kJ} \mathrm{mol}}\end{array}$ & $S_{\text {avg }}(\mathrm{SD} ; \mathrm{SE})$ & $\Delta T_{\mathrm{avg}}(\mathrm{SD} ; \mathrm{SE})\left[{ }^{\circ} \mathrm{C}\right]$ \\
\hline $\mathrm{C} 1$ & Sealed test tube & 110 & 50 & 5 & 15 & $1.32(0.57 ; 0.054)$ & $1.76(0.43 ; 0.041)$ & $23(10.7 ; 1.02)$ \\
\hline $\mathrm{C} 2$ & Sealed test tube & 84 & 45 & 5 & 15 & $1.36(0.48 ; 0.052)$ & $1.79(0.38 ; 0.041)$ & $24(9.3 ; 1.01)$ \\
\hline C3 & Sealed test tube & 70 & 50 & 10 & 15 & $1.86(0.42 ; 0.051)$ & $2.23(0.43 ; 0.052)$ & $34(8.6 ; 1.02)$ \\
\hline $\mathrm{C} 4$ & Sealed test tube & 112 & 50 & 20 & 15 & $1.96(0.40 ; 0.038)$ & $2.32(0.41 ; 0.038)$ & $35.9(8.1 ; 0.76)$ \\
\hline C5 & Open crystallizer & 10 & 50 & 20 & 150 & $0.80(0.30 ; 0.096)$ & $1.38(0.18 ; 0.057)$ & $14(5.4 ; 1.71)$ \\
\hline C6 & Sealed crystallizer & 10 & 50 & 20 & 150 & $1.20(0.28 ; 0.087)$ & $1.62(0.22 ; 0.068)$ & $21(5.2 ; 1.66)$ \\
\hline
\end{tabular}

(Tables 1-5). The investigated experimental conditions are saturation temperature $\left(T_{\text {eq }}\right)$, cooling rate $(-\mathrm{d} T / \mathrm{d} t)$, solution volume $\left(V_{\text {soln }}\right)$, and type of vessel used. The MZW is given as the average thermodynamic driving force approximated through eqn (2), $[R T \ln S]_{\mathrm{avg}}$, the average supersaturation, $S_{\text {avg, }}$, and the average undercooling, $\Delta T_{\text {avg }}$, at the onset of nucleation, all calculated as the arithmetic mean. The standard deviations (SD) and standard errors (SE) are given in parentheses. The distributions of the nucleation events with the temperature obtained in different solvents at different saturation temperatures are shown in Fig. 2, for a cooling rate of $5{ }^{\circ} \mathrm{C} \mathrm{h}^{-1}$ and a solution volume of $15 \mathrm{ml}$. It is evident that repeated cooling crystallizations performed under identical experimental conditions result in nucleation occurring over a wide temperature range. A wide distribution in the MZW was observed for all solvents and experimental conditions. A similar variability was observed for each solution maintained in the same vessel during consecutive dissolution-recrystalli- zation experiments. Hence, the distribution in the data cannot be explained as emanating from inherent differences in the crystallizer vessels (e.g. imperfections in the vessel glass or differences in the stirrer bars), history of solution, or in the properties of each individual solution (e.g. impurities, particulates or small concentration differences).

As shown in Tables 1-5 and in Fig. 2, the nucleation event distributions are very broad, especially in acetic acid and ethyl acetate, reaching a range of variation of about $35{ }^{\circ} \mathrm{C}$. At the 15 $\mathrm{ml}$ scale for a cooling rate of $5{ }^{\circ} \mathrm{C} \mathrm{h}^{-1}$, the average metastable zone width in acetonitrile is less than $10{ }^{\circ} \mathrm{C}$ and decreases when the saturation temperature/concentration is decreased. In methanol the metastable zone width is slightly wider and does not systematically change with the saturation temperature. In acetone, the MZW is between 10 and $20{ }^{\circ} \mathrm{C}$ and tends to decrease when the temperature is increased. In ethyl acetate and acetic acid the widest metastable zone widths are found.

Table 4 Nucleation experiments in acetone (423 experiments)

\begin{tabular}{|c|c|c|c|c|c|c|c|c|}
\hline \multirow[b]{2}{*}{ No. } & \multirow[b]{2}{*}{ Vessel type } & \multirow[b]{2}{*}{ Experiments } & \multicolumn{3}{|c|}{ Parameters } & \multicolumn{3}{|c|}{ MZW } \\
\hline & & & $T_{\text {eq }}\left[{ }^{\circ} \mathrm{C}\right]$ & $\begin{array}{l}-\mathrm{d} T / \mathrm{d} t \\
{\left[{ }^{\circ} \mathrm{C} \mathrm{h}^{-1}\right]}\end{array}$ & $V_{\text {soln }}[\mathrm{ml}]$ & $\begin{array}{l}{[R T \ln S]_{\mathrm{avg}}(\mathrm{SD} ; \mathrm{SE})} \\
{\left[\mathrm{kJ} \mathrm{\textrm {mol } ^ { - 1 } ]}\right.}\end{array}$ & $S_{\text {avg }}(\mathrm{SD} ; \mathrm{SE})$ & $\Delta T_{\mathrm{avg}}(\mathrm{SD} ; \mathrm{SE})\left[{ }^{\circ} \mathrm{C}\right]$ \\
\hline D1 & Sealed test tube & 70 & 50 & 5 & 15 & $0.54(0.25 ; 0.030)$ & $1.24(0.13 ; 0.016)$ & $12.4(5.9 ; 0.71)$ \\
\hline D2 & Sealed test tube & 70 & 45 & 5 & 15 & $0.67(0.27 ; 0.032)$ & $1.32(0.15 ; 0.018)$ & $15.7(6.5 ; 0.78)$ \\
\hline D3 & Sealed test tube & 51 & 40 & 5 & 15 & $0.84(0.27 ; 0.038)$ & $1.42(0.16 ; 0.023)$ & $20.0(6.7 ; 0.94)$ \\
\hline D4 & Sealed test tube & 54 & 35 & 5 & 15 & $0.73(0.36 ; 0.049)$ & $1.38(0.23 ; 0.031)$ & $18(9.1 ; 1.23)$ \\
\hline D5 & Sealed test tube & 71 & 50 & 10 & 15 & $0.81(0.37 ; 0.044)$ & $1.40(0.22 ; 0.026)$ & $19(8.9 ; 1.06)$ \\
\hline D6 & Sealed test tube & 87 & 50 & 20 & 15 & $0.88(0.29 ; 0.031)$ & $1.43(0.17 ; 0.019)$ & $20.6(7.0 ; 0.76)$ \\
\hline D7 & Open crystallizer & 10 & 50 & 20 & 150 & $0.36(0.10 ; 0.032)$ & $1.15(0.05 ; 0.014)$ & $8.0(2.3 ; 0.73)$ \\
\hline D8 & Sealed crystallizer & 10 & 50 & 20 & 150 & $0.46(0.09 ; 0.027)$ & $1.19(0.04 ; 0.013)$ & $10.4(2.0 ; 0.62)$ \\
\hline
\end{tabular}

Table 5 Nucleation experiments in ethyl acetate (491 experiments)

\begin{tabular}{|c|c|c|c|c|c|c|c|c|}
\hline \multirow[b]{2}{*}{ No. } & \multirow[b]{2}{*}{ Vessel type } & \multirow[b]{2}{*}{ Experiments } & \multicolumn{3}{|c|}{ Parameters } & \multicolumn{3}{|c|}{ MZW } \\
\hline & & & $T_{\text {eq }}\left[{ }^{\circ} \mathrm{C}\right]$ & $\begin{array}{l}-\mathrm{d} T / \mathrm{d} t \\
{\left[{ }^{\circ} \mathrm{C} \mathrm{h}^{-1}\right]}\end{array}$ & $V_{\text {soln }}[\mathrm{ml}]$ & 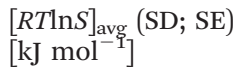 & $S_{\text {avg }}(\mathrm{SD} ; \mathrm{SE})$ & $\Delta T_{\mathrm{avg}}(\mathrm{SD} ; \mathrm{SE})\left[{ }^{\circ} \mathrm{C}\right]$ \\
\hline E1 & Sealed test tube & 126 & 50 & 5 & 15 & $0.94(0.34 ; 0.030)$ & $1.47(0.21 ; 0.019)$ & $17.6(6.7 ; 0.60)$ \\
\hline E2 & Sealed test tube & 65 & 45 & 5 & 15 & $1.11(0.40 ; 0.049)$ & $1.60(0.29 ; 0.036)$ & $22(8.5 ; 1.05)$ \\
\hline E3 & Sealed test tube & 140 & 50 & 10 & 15 & $1.34(0.36 ; 0.030)$ & $1.75(0.28 ; 0.024)$ & $25.8(7.6 ; 0.65)$ \\
\hline $\mathrm{E} 4$ & Sealed test tube & 140 & 50 & 20 & 15 & $1.23(0.41 ; 0.035)$ & $1.67(0.30 ; 0.025)$ & $23.5(8.5 ; 0.72)$ \\
\hline E5 & Open crystallizer & 10 & 50 & 20 & 150 & $0.84(0.30 ; 0.095)$ & $1.40(0.18 ; 0.056)$ & $16(5.9 ; 1.86)$ \\
\hline E6 & Sealed crystallizer & 10 & 50 & 20 & 150 & $1.0(0.32 ; 0.103)$ & $1.48(0.19 ; 0.061)$ & $18(6.4 ; 2.02)$ \\
\hline
\end{tabular}



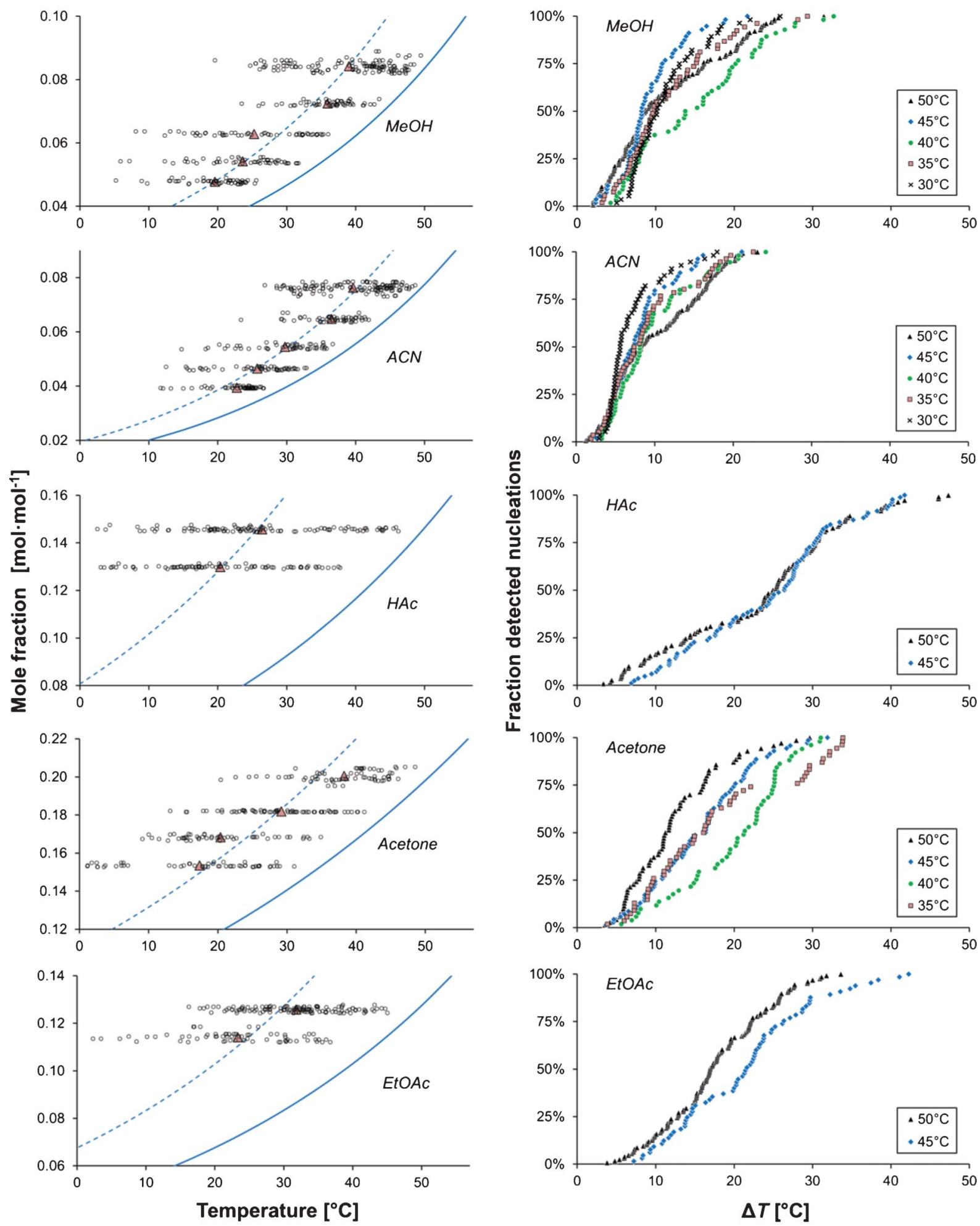

Fig. 2 The onset temperature of nucleation (left) and the cumulative distribution of detected nucleation events with undercooling temperature (right) for different saturation temperatures, shown for five solvents $\left(V_{\text {soln }}=15 \mathrm{ml},-\mathrm{d} T / \mathrm{d} t=5^{\circ} \mathrm{C} \mathrm{h}^{-1}\right)$. The red triangles indicate mean values, the solid lines show the solubility and dashed lines show the average $\Delta T$.

Although the traditional way of presenting the metastable zone widths in terms of the degree of undercooling is useful from an industrial perspective, an analysis in terms of the chemical potential driving force or a corresponding simplified measure, eqn (2), is required in order to advance the understanding of the effect of various conditions on nuclea- 

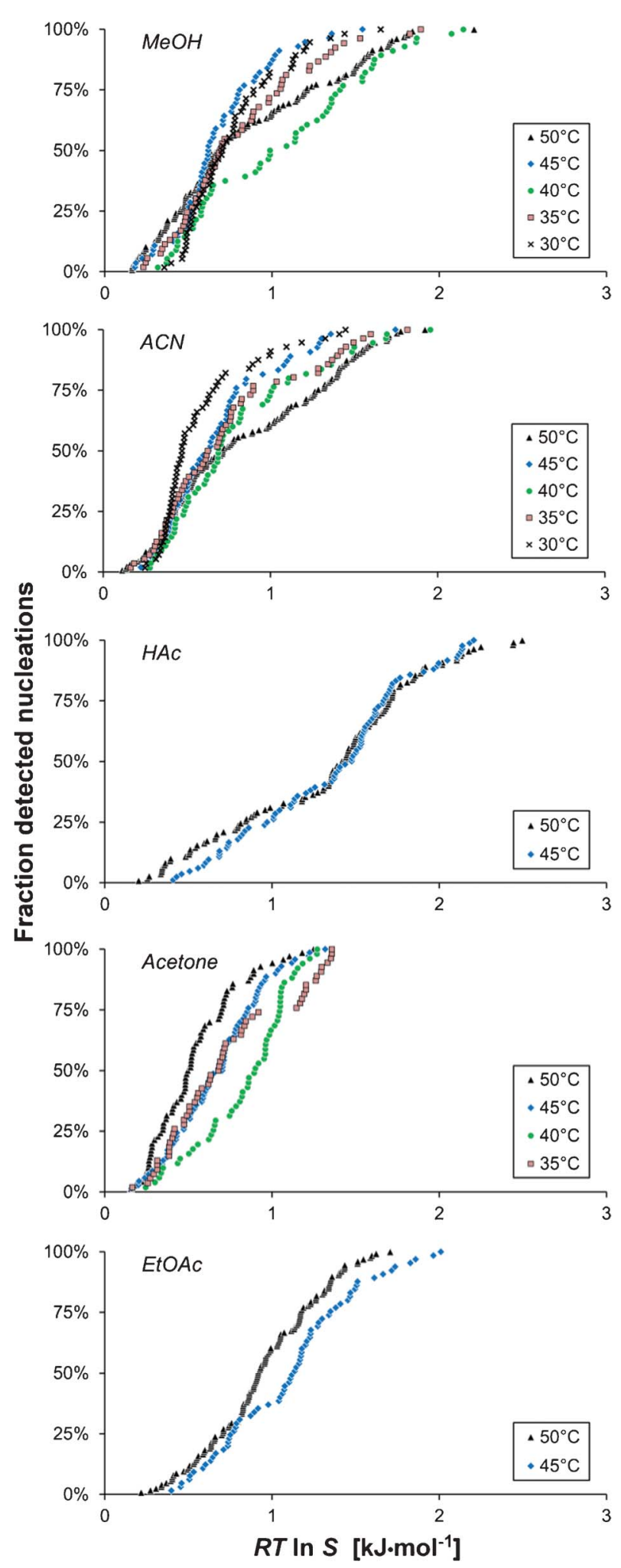

Fig. 3 The cumulative distribution of the detected nucleation events with driving force for the nucleation, shown for five solvents $\left(V_{\text {soln }}=15 \mathrm{ml}\right.$ and $-\mathrm{d} T$ / $\left.\mathrm{d} t=5^{\circ} \mathrm{C} \mathrm{h}^{-1}\right)$ for different saturation temperatures: $50^{\circ} \mathrm{C}(\mathrm{A} 1$, black triangles), $45^{\circ} \mathrm{C}$ ( $\mathrm{A} 2$, blue diamonds), $40{ }^{\circ} \mathrm{C}$ ( $\mathrm{A} 3$, green circles), $35^{\circ} \mathrm{C}$ ( $\mathrm{A} 4$, red boxes) and $30{ }^{\circ} \mathrm{C}(\mathrm{A} 5$, crosses). tion. In Fig. 3 the above distributions of the nucleation events are shown in terms of $R T \ln S$. The driving force distributions obtained for each solvent are qualitatively similar to the corresponding $\Delta T$-distributions (Fig. 2.) However, comparing the experiments in the $15 \mathrm{ml}$ scale with a cooling rate of $5{ }^{\circ} \mathrm{C}$ $\mathrm{h}^{-1}$ reveals that nucleation in acetone requires the lowest average driving force, followed by methanol, acetonitrile and ethyl acetate, with the highest driving force required for nucleation in acetic acid; this order deviates from that obtained with respect to the degree of undercooling. This reflects the influence of the slope of the solubility curve, which is investigated in more detail below. It is notable that the distributions of the nucleation events with respect to $R T \ln S$ are relatively wide, and not markedly more compacted than the undercooling distributions, which is in contrast to the behaviour observed for other chemically related compounds. ${ }^{15-17}$

Within each series of experiments performed under identical experimental conditions $\left(V_{\text {soln }}=15 \mathrm{ml}, T_{\text {eq }}=50{ }^{\circ} \mathrm{C}\right.$ and $-\mathrm{d} T / \mathrm{d} t=5^{\circ} \mathrm{C} \mathrm{h}^{-1}$ ), the supersaturation ratio at nucleation spans a range from 1.08 to 2.97 in acetic acid and from 1.06 to 1.67 in acetone, corresponding to a driving force ranging from 0.20 to $2.50 \mathrm{~kJ} \mathrm{~mol}^{-1}$ in acetic acid and from 0.16 to $1.25 \mathrm{~kJ}$ $\mathrm{mol}^{-1}$ in acetone. The case is similar for the other three solvents.

The distribution of the nucleation events is a manifestation of the stochastic nature of nucleation in these experiments observed under dynamic conditions of decreasing temperature. When the temperature is decreased the driving force for the nucleation increases, and the kinetics of the various rate processes leading to the nucleation change with temperature as well. As a consequence, no simple statistical distribution is expected to provide a strictly valid representation. In the present work, it has been empirically found that the arithmetic mean of $R T \ln S$ corresponds closely to the mode of the distribution. In Fig. 4, the mean thermodynamic driving force at nucleation is shown graphically for all experimental series, together with the associated $95 \%$ confidence limits calculated by approximating normal distributions.

With the possible exceptions of cooling crystallizations in methanol and acetonitrile in open crystallizers (A10-A11 and B8-B9), the variation in the onset of nucleation elucidates the problems associated with the concept of a constant MZW for a given set of experimental conditions. As shown in Fig. 5 there is a linear correlation between the magnitude of the width of the distribution and the average supersaturation ratio, $S_{\text {avg. }}$. The coefficient of variation around the straight line, given as $100 \cdot \mathrm{SD} /\left(S_{\text {avg }}-1\right)$, equals $44 \%$.

\section{Analysis and discussion}

In the following analysis, the focus is on analysing the impact of various process variables. No distinction is made of whether the nucleation is homogeneous or heterogeneous; it is sufficient for the purpose of this analysis that the basic 


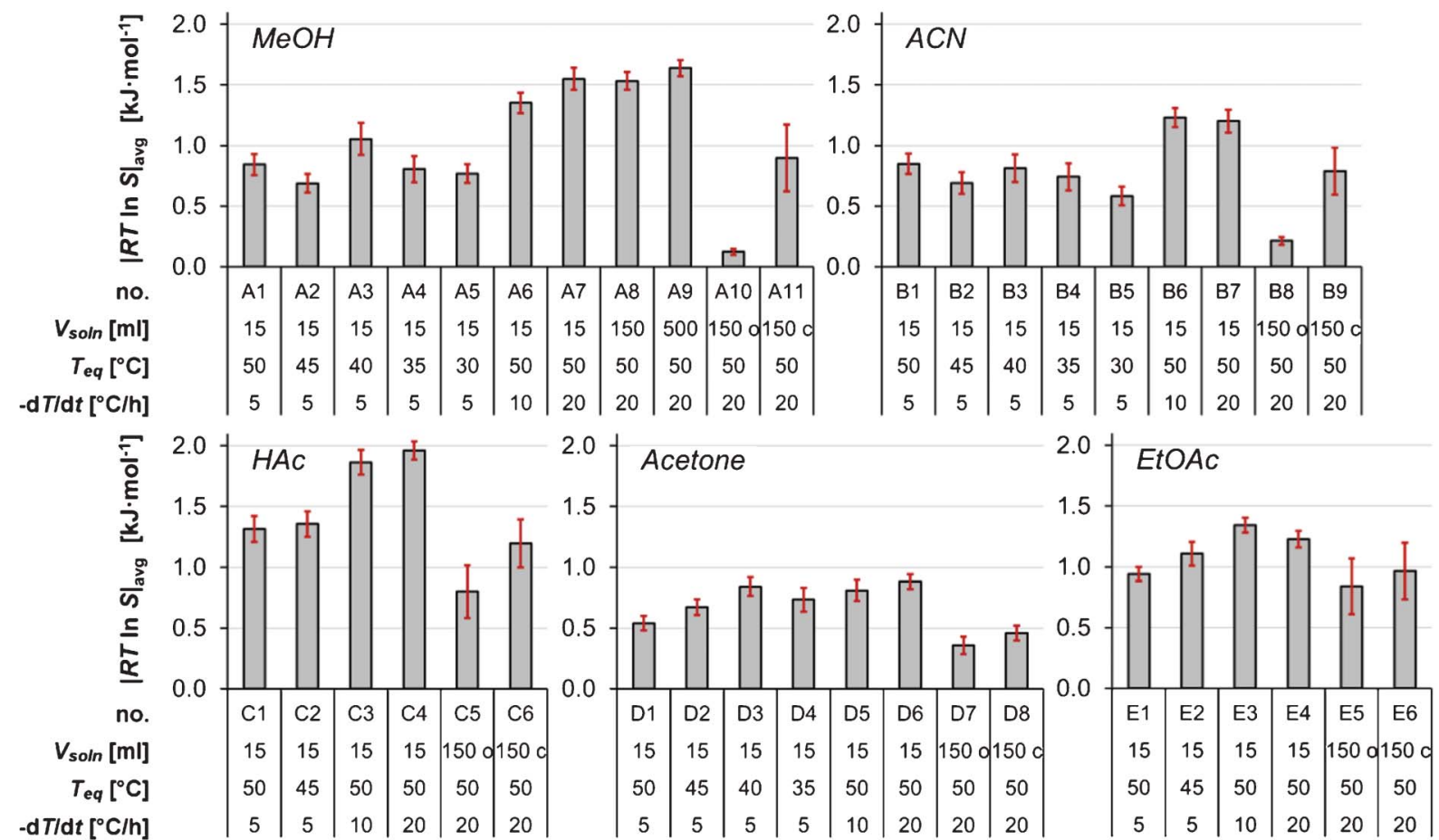

Fig. 4 The average thermodynamic driving force for nucleation for all experimental series, with error bars showing $95 \%$ confidence intervals.

functional forms of the equations used are the same as outlined in the theory section.

\section{The influence of the saturation temperature and cooling rate}

In acetone as shown in Fig. 4, the mean driving force required for nucleation increases with a decrease in the saturation temperature down to $T_{\mathrm{eq}}=40{ }^{\circ} \mathrm{C}$, in the $15 \mathrm{ml}$ scale at a cooling rate of $5{ }^{\circ} \mathrm{C} \mathrm{h}^{-1}$. This is in accordance with expectations, since the rates of various kinetic phenomena are slower at lower temperatures. The same observation is made for the more limited data in ethyl acetate. However, it is noted that the trend is not sustained with further decreases of $T_{\mathrm{eq}}$ in acetone,

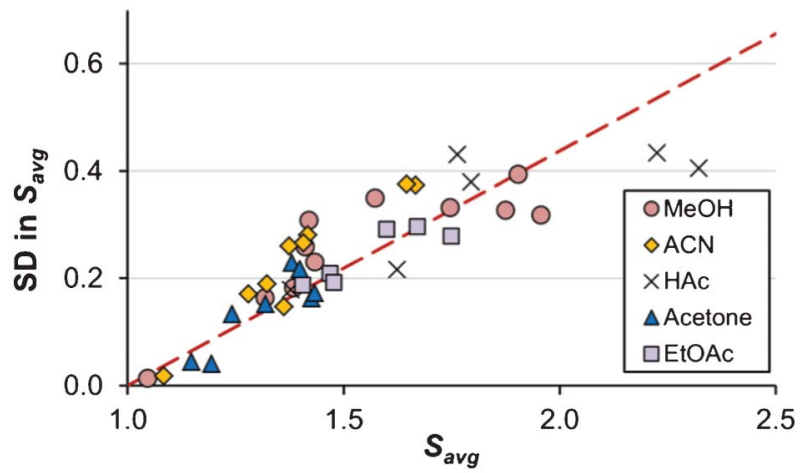

Fig. 5 The relationship between the supersaturation at the average onset of nucleation ( $x$-axis) and its associated standard deviation ( $y$-axis) for solutions of methanol (red circles), acetonitrile (yellow diamonds), acetic acid (crosses), acetone (blue triangles) and ethyl acetate (purple boxes). Data from all experimental conditions (Tables 1-5). and in acetic acid, methanol and acetonitrile there is no clear trend at all.

The influence of the cooling rate on the MZW is shown in Fig. 6 as the average degree of undercooling versus the cooling rate for five solvents. As expected, the metastable zone width increases with an increasing cooling rate. This effect was particularly evident when comparing the cooling rates of 5 and $10{ }^{\circ} \mathrm{C} \mathrm{h}^{-1}$, and in methanol and acetone. It has been suggested $^{6,18}$ that there should be a linear relationship between $\ln \Delta T$ and $\ln (-\mathrm{d} T / \mathrm{d} t)$. Obviously, no clear linear correlation can be observed in Fig. 6, and consequently we

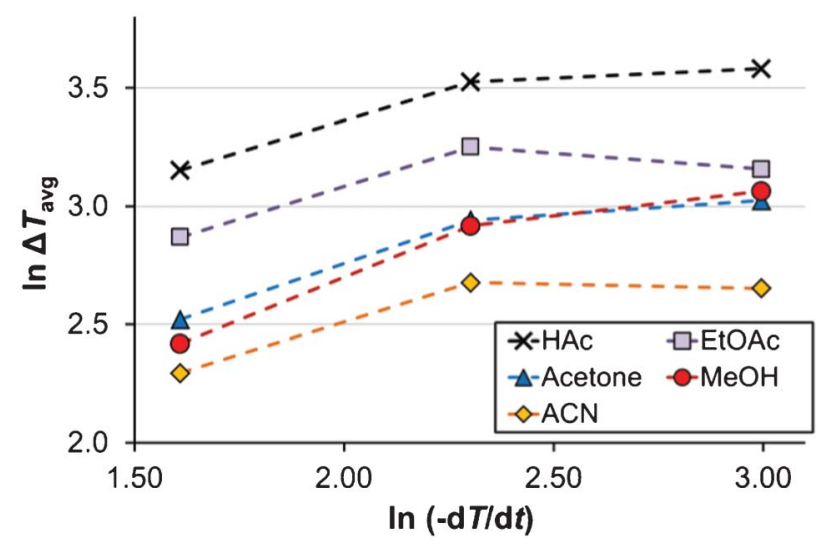

Fig. 6 The relationship between undercooling at the average onset of nucleation and the cooling rate $\left(V_{\text {soln }}=15 \mathrm{ml}, T_{\text {eq }}=50^{\circ} \mathrm{C}\right)$ in methanol (red, circles), acetonitrile (yellow, diamonds), acetic acid (black, crosses), acetone (blue, triangles) and ethyl acetate (purple, boxes). Lines are tie-lines only. 


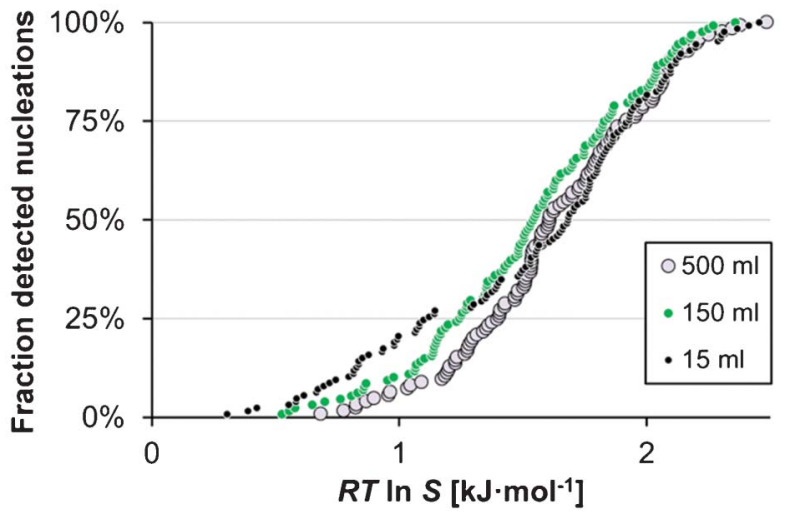

Fig. 7 The cumulative distribution of the detected nucleation events in methanol $\left(T_{\text {eq }}=50{ }^{\circ} \mathrm{C},-\mathrm{d} T / \mathrm{d} t=20^{\circ} \mathrm{C} \mathrm{h}^{-1}\right)$ in $15 \mathrm{ml}(\mathrm{A} 7$, black), $150 \mathrm{ml}$ (A8, green) and $500 \mathrm{ml}$ (A9, white).

have refrained from estimating the apparent nucleation order by the approach proposed by Nývlt. ${ }^{7}$

\section{The influence of the solution volume}

The effect of the solution volume on the MZW of salicylamide was investigated in methanol at a cooling rate of $20{ }^{\circ} \mathrm{C} \mathrm{h}^{-1}$ (A7-A9 in Table 1) using three different solution volumes, viz. 15, 150 and $500 \mathrm{ml}$. As shown in Fig. 7, both the average onset of nucleation as well as the overall shape and spread of the distribution were found to be essentially unaffected by the solution volume. Interestingly, the observed lack of influence of the solution volume on the MZW distribution is in contradiction with results reported by Kadam et al. ${ }^{19,20}$ and with the proposed single nucleus mechanism, wherein it is assumed that as soon as one single nucleus is formed and has grown to sufficient size it undergoes massive secondary nucleation. Given the assumption that the probability of a single primary nucleation event occurring in a solution within a given space of time $\mathrm{d} t$ is proportional to $J V \mathrm{~d} t,^{21}$ a single nucleus mechanism entails that the average metastable zone width should be smaller in a larger volume and the distribution of nucleation events should have a lower coefficient of variation; a behaviour which is completely absent from the distributions shown in Fig. 7.

\section{The influence of the crystallizer design}

In the present work, the nucleation experiments in methanol at the $150 \mathrm{ml}$ scale show a decreased MZW of salicylamide when switching from a sealed bottle to a sealed jacketed crystallizer. The MZW of salicylamide in methanol in the crystallizers amounted to $S_{\text {avg }}=1.43 \pm 0.17$ (A11), compared to $S_{\text {avg }}=1.87 \pm 0.06$ (A8) in the bottles, corresponding to driving forces for nucleation of $0.90 \pm 0.28 \mathrm{~kJ} \mathrm{~mol}^{-1}$ and $1.53 \pm 0.07$ $\mathrm{kJ} \mathrm{mol}^{-1}$, respectively (95\% confidence limits in parentheses). Although only 10 experiments were repeated in the jacketed crystallizers and acknowledging the large spread in the data, the difference is sufficiently significant not to be disregarded as merely a statistical artifact. As the cooling crystallizations were performed using identical experimental conditions, i.e. cooling rate, saturation temperature, solution volume and

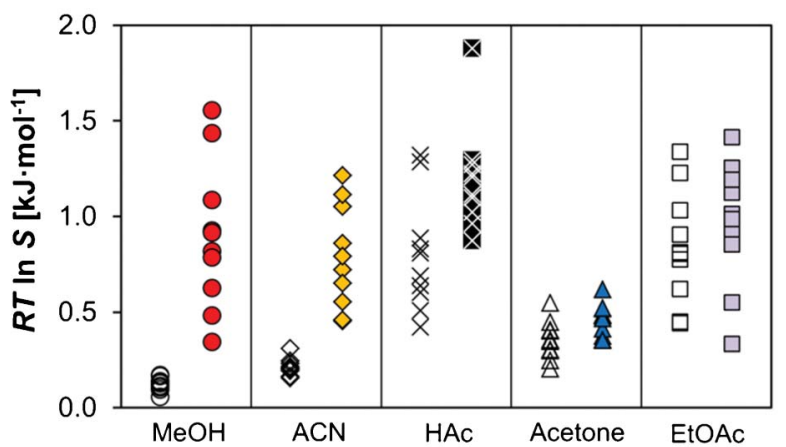

Fig. 8 A comparison of the driving force required for nucleation in open (hollow symbols) and sealed (filled symbols) crystallizers $\left(T_{\text {eq }}=50{ }^{\circ} \mathrm{C},-\mathrm{d} T / \mathrm{d} t=20^{\circ} \mathrm{C}\right.$ $\left.\mathrm{h}^{-1}\right)$ in methanol $(\mathrm{A} 10, \mathrm{~A} 11)$, acetonitrile $(\mathrm{B} 8, \mathrm{~B} 9)$, acetic acid $(\mathrm{C} 5, \mathrm{C} 6)$, acetone (D7, D8) and ethyl acetate (E5, E6).

stirring rate, the difference in the MZW is attributed to the differences in the vessel design, which results in differences in the hydrodynamic conditions and a varying degree of inhomogeneities in temperature and concentration.

Measurements of the MZW were also conducted in open jacketed crystallizers where the solution was exposed to the surrounding air (using no crystallizer lid), as opposed to the standard procedure in this work where evaporation was prevented by using airtight caps. The results are shown in Fig. 8. Depending on solvent, the results reveal a sometimes dramatic change in the MZW distributions: the mean values of $R T \ln S$ at nucleation decrease from 0.90 (A11) to 0.12 (A10) in methanol, and from 0.79 (B9) to 0.21 (B8) in acetonitrile upon the removal of the crystallizer lid, with a corresponding reduction in the associated standard deviations from 0.38 to 0.03 in methanol and from 0.27 to 0.04 in acetonitrile. Thus, a significantly increased repeatability is obtained in the observed onset of nucleation for open crystallizers. The corresponding behaviour in acetic acid, acetone and ethyl acetate is not as notable. Although for all three solvents the average MZW did decrease to some extent in the experiments where the crystallizer lid was removed, the differences when considering the entire distributions of the nucleation events are not that significant.

The significant difference in the onset of nucleation of salicylamide in solutions of methanol and acetonitrile between crystallizers with and without lid suggests that in these cases, the evaporation of the solvent has a major influence on the nucleation kinetics. The evaporation of the solvent will result in a concentration gradient as well as a temperature gradient in the solution close to the surface, which may provide localized regions of higher supersaturation which in turn facilitate nucleation. The significant difference in the onset of nucleation of salicylamide in solutions of methanol and acetonitrile between crystallizers with and without lid suggests that in these cases, the evaporation of the solvent has a major influence on the nucleation kinetics. However, the absence of a significant difference in the MZW between open and closed crystallizers in acetic acid, acetone and ethyl acetate suggests that the effects of the solvent evaporation are less important for these solvents. It might have been expected that the 
nucleation in acetone, with the lowest boiling point and highest volatility of the investigated solvents, should be substantially facilitated by evaporation, but this was not observed, nor is there a correlation to the surface tension of the solvent.

It is possible that the reduction in the MZW in solutions of methanol and acetonitrile in open crystallizers could be due to the effect of a different nucleation mechanism in these solvents, where incidentally the mole fraction solubility is the lowest. The onset of nucleation in methanol and acetonitrile in open crystallizers was always seen to be preceded by a thin layer of crystals forming on the glass wall adjacent to the solution surface, but such a scaling process was never observed for the closed crystallizers or in the other three solvents.

\section{The influence of the solvent}

Of all the investigated experimental parameters, the choice of solvent was arguably found to exert the strongest effect on the onset of nucleation of salicylamide. The cumulative distributions in different solvents are compared in Fig. 9 for different saturation temperatures. The narrowest MZW was obtained in acetone, where the mean nucleation driving force $\left(15 \mathrm{ml}, T_{\mathrm{eq}}=\right.$ $50{ }^{\circ} \mathrm{C},-\mathrm{d} T / \mathrm{d} t=5{ }^{\circ} \mathrm{C} \mathrm{h}^{-1}$ ) is $0.54 \mathrm{~kJ} \mathrm{~mol}^{-1}$, which corresponds to an undercooling of $12.4{ }^{\circ} \mathrm{C}$. For similar experimental conditions acetic acid resulted in the widest MZW of all the investigated solvents, with a mean nucleation driving force of $1.32 \mathrm{~kJ} \mathrm{~mol}^{-1}$, which corresponds to an undercooling of 23.4 ${ }^{\circ} \mathrm{C}$. Intermediate values were obtained in acetonitrile, methanol and ethyl acetate, where the distributions for this set of experimental conditions overlap and the differences cannot be resolved with statistical significance. However, experiments at lower saturation temperatures indicate that the driving force for nucleation increases in the order acetonitrile $<$ methanol $<$ ethyl acetate.

For a given cooling rate, supersaturation will be generated at a different rate in different solvents. In Fig. 10a, the supersaturation is shown as a function of undercooling temperature for all five solvents for the experiments with a saturation temperature of $50{ }^{\circ} \mathrm{C}$, with nucleation events for the experiments carried out at a cooling rate of $5{ }^{\circ} \mathrm{C} \mathrm{h}^{-1}$ plotted on each curve. The rate of generation of $R T \ln S$ is approximately constant in all solvents over the investigated temperature range. In Fig. 10b, the average change in supersaturation with undercooling is plotted against $\ln x_{\mathrm{eq}, 50^{\circ} \mathrm{C}}$. The rate of supersaturation generation decreases in the order acetonitrile $>$ methanol $>$ acetic acid $>$ ethyl acetate $>$ acetone, and shows a relatively clear inverse correlation to the mole fraction solubility ${ }^{4}$ (which is highest in acetone, followed by acetic acid, ethyl acetate, and then by methanol and acetonitrile). Such a correlation is expected ${ }^{22}$ and has been observed for similar compounds. ${ }^{15,17}$ However, there is no correlation between the ease of nucleation, in terms of the mean $R T \ln S$, neither with the solubility nor with the rate of supersaturation generation. Apparently, the solvent influence on the nucleation of salicylamide has a more complex behaviour.

In nucleation from melts, it has been reported that with an increased undercooling, the anticipated increase in the nucleation rate due to an increasing driving force can be

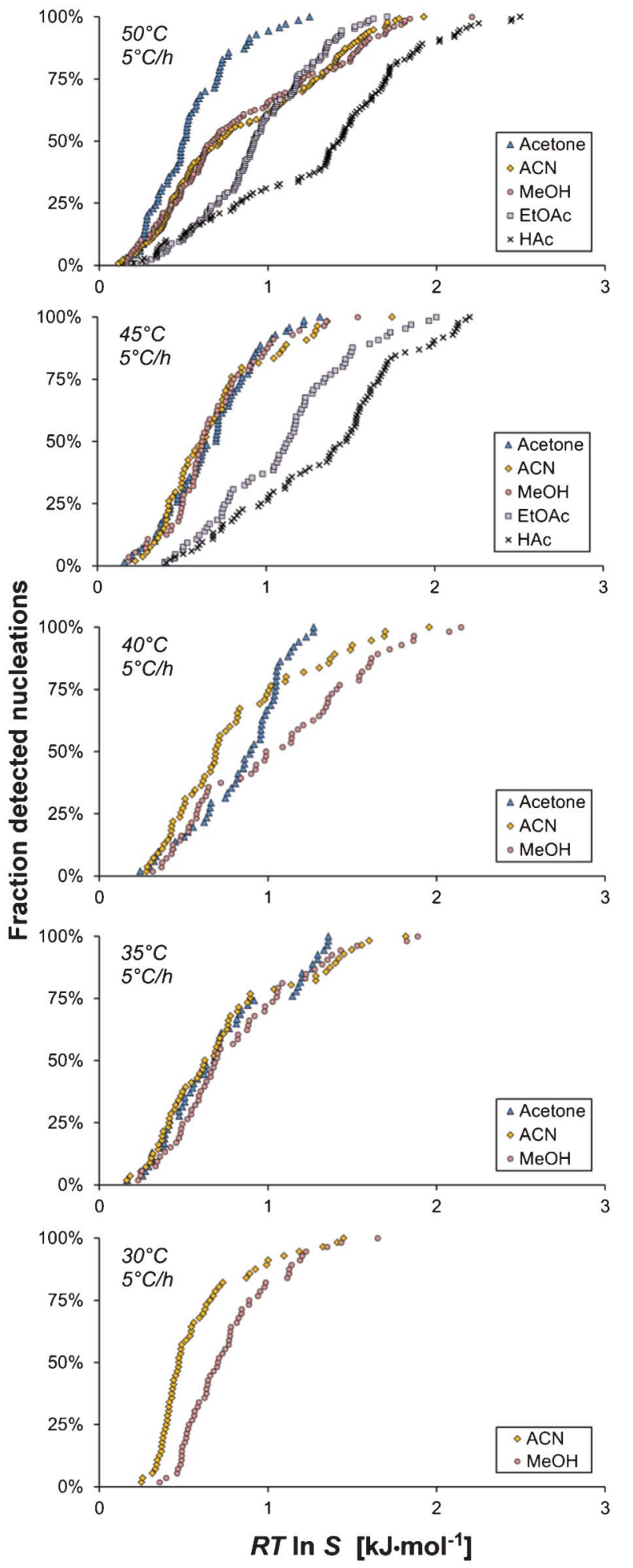

Fig. 9 The cumulative distribution of the detected nucleation events with driving force for nucleation, shown for five saturation temperatures $\left(V_{\text {soln }}=15\right.$ $\mathrm{ml}$ and $\left.-\mathrm{d} T / \mathrm{d} t=5{ }^{\circ} \mathrm{Ch}^{-1}\right)$ for different solvents: methanol (A1-A5, red circles), acetonitrile (B1-B5, yellow diamonds), acetic acid (C1-C2, crosses), acetone (D1D4, blue triangles) and ethyl acetate (E1-E2, purple boxes). 

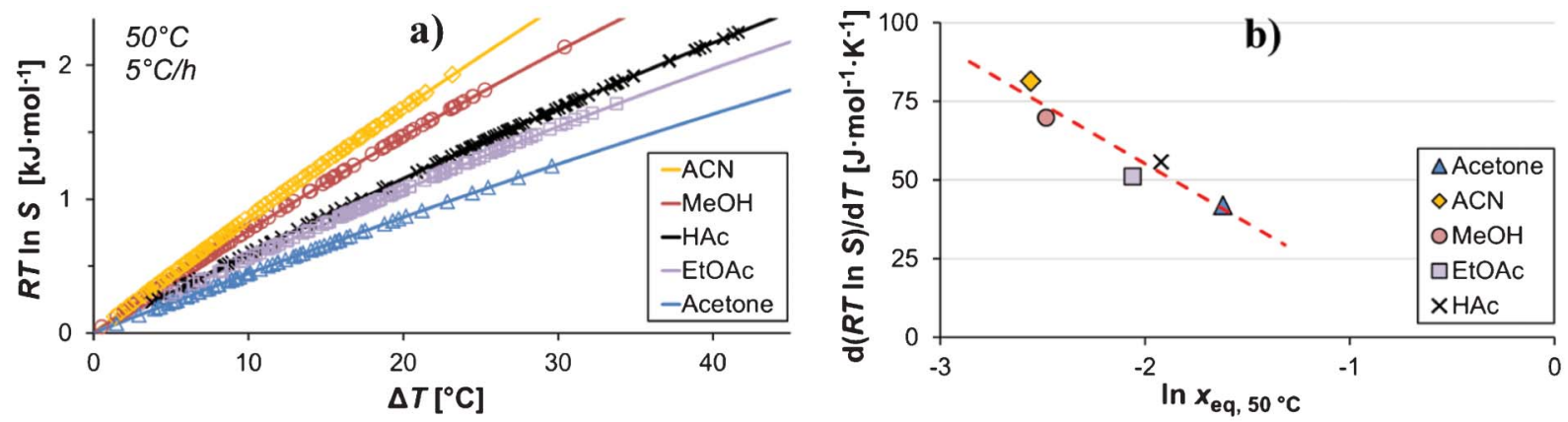

Fig. 10 a) The generated nucleation driving force vs. the undercooling temperature for the five solvents with the nucleation events plotted on the respective curve, and $\mathrm{b})$ the temperature derivative of the nucleation driving force $v$. the mole fraction solubility $\left(T_{\text {eq }}=50{ }^{\circ} \mathrm{C},-\mathrm{d} T / \mathrm{d} t=5{ }^{\circ} \mathrm{C} \mathrm{h}{ }^{-1}\right)$.

counteracted by an increase in the viscosity, resulting in the nucleation rate reaching a maximum value at a certain level of undercooling beyond which it decreases. ${ }^{29}$ Such behaviour has also been observed for viscous supersaturated solutions of citric $\operatorname{acid}^{30}$ as well as for the protein crystallization of lysozyme. ${ }^{31}$ In the present study, no clear correlation could be established between the average MZW and the various individual physicochemical properties of the solvent, viz. boiling point, polarity, viscosity, density or molecular weight. However, as is shown in Fig. 11, for all three cooling rates there is a clear linear correlation $\left(R^{2}>0.95\right)$ between the average supersaturation ratio at the onset of nucleation and the viscosity of the solvent divided by the solute concentration in solution $\left(\mathrm{mol} \mathrm{m}^{-3}\right)$ times the square root of the solvent molar mass; a parameter group appearing in eqn (10). There is little difference in the linear slope obtained for the three cooling rates, but there is a displacement such that a higher supersaturation is systematically required for nucleation at higher cooling rates.
As discussed in the theory section, the parameter group used as the independent parameter in Fig. 11 originates from the attachment frequency factor. The square root of the solvent molecular weight divided by the viscosity is proportional to the diffusivity via the Stokes-Einstein equation and hence to the molecular mobility in the solution, and dividing by the concentration gives a parameter related to the frequency by which the free solute molecules collide with a cluster surface. $\eta / C \sqrt{M}$ increases in the order acetone $<$ ethyl acetate $<$ acetonitrile $<$ methanol $<$ acetic acid. Among these solvents the viscosity is lowest in acetonitrile but the saturation concentration of salicylamide is about twice as high in acetone, which might explain why nucleation is easiest in this solvent. At the other end of the scale, in acetic acid the solubility is quite high, but due to a high viscosity the molecular mobility will be significantly lower. Naturally, at a molecular level more complex mechanisms could also contribute; the solvent has been shown to influence the aggregation of the molecules in solution ${ }^{32,33}$ and the relative growth rate of different crystal faces through selective adsorp-

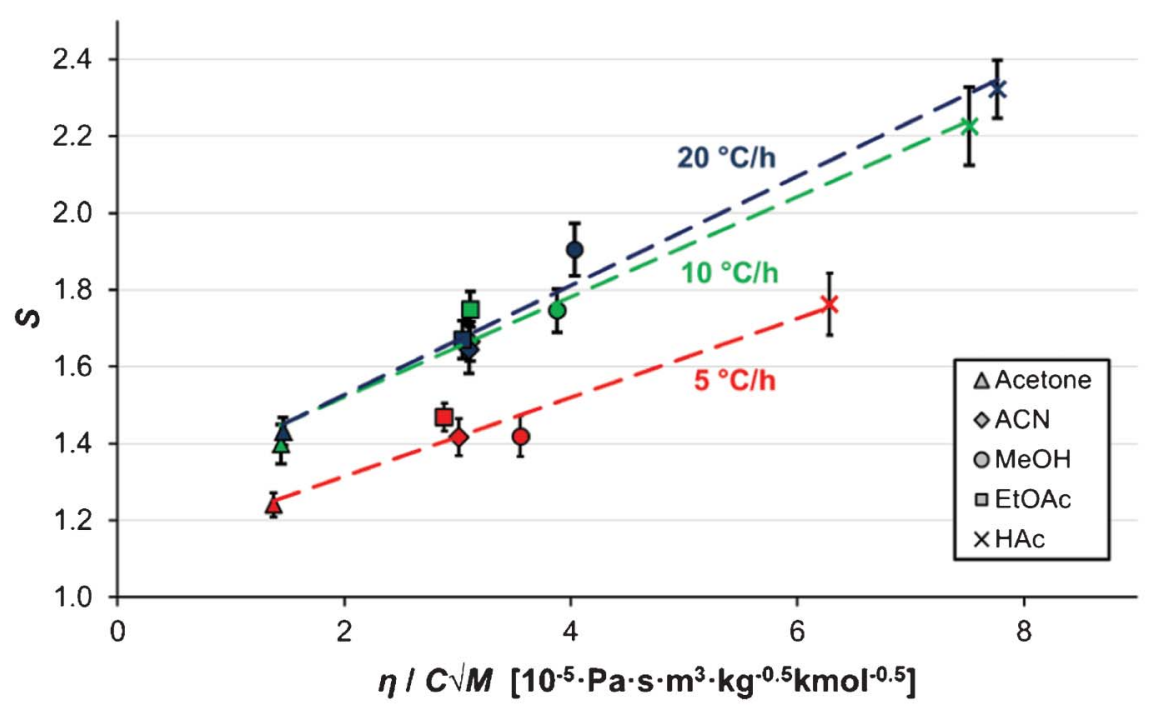

Fig. 11 The dependence of the average supersaturation at nucleation on the solvent viscosity, molar mass and solute molar concentration $\left(V_{\text {soln }}=15 \mathrm{ml}, T_{\text {eq }}=50{ }^{\circ} \mathrm{C}\right)$, for cooling rates of $5{ }^{\circ} \mathrm{Ch}^{-1}$ (red) $10^{\circ} \mathrm{Ch}^{-1}$ (green) and $20^{\circ} \mathrm{Ch}^{-1}$ (dark blue). The error bars represent $95 \%$ confidence limits. The viscosity values are from Xiang et al. (2006), ${ }^{23}$ Nikam et al. (1998), ${ }^{24}$ Narayan et al. (1988), ${ }^{25}$ Moreno et al. (2001), ${ }^{26}$ Hazra and Venkateswarlu (1978), ${ }^{27}$ and Bleazard et al. (1996). ${ }^{28}$ 
tion. ${ }^{34}$ It is worth noting that when exchanging $S$ for $R T \ln S$ the linear fits are only marginally worse, and also that a similar kind of correlation has been reported for the nucleation of the two polymorphs of the compound $m$-hydroxybenzoic acid. ${ }^{15}$

\section{Conclusions}

The metastable zone width for the nucleation of salicylamide at a constant cooling rate is shown to be fairly independent upon saturation temperature in the interval of $30-50{ }^{\circ} \mathrm{C}$, while an increased cooling rate is shown to lead to a larger metastable zone in five common organic solvents. The average metastable zone width is found to decrease when the solvent is allowed to evaporate during the cooling crystallization compared to the case of a sealed crystallizer; in two out of five solvents (methanol and acetonitrile) this change is dramatic. No detectable influence on the metastable zone width of the crystallizer volume in the range $15-500 \mathrm{ml}$ is seen for nucleations in methanol, but switching from a sealed bottle to a sealed, jacketed crystallizer resulted in a statistically significant decrease in the metastable zone width.

Of the investigated parameters, the choice of solvent is shown to exert the strongest influence on the metastable zone width. A correlation has been found between the average supersaturation ratio at nucleation and a representation of the attachment frequency factor. This correlation holds for all solvents at different cooling rates.

The onset of nucleation of salicylamide is found to vary significantly between reproducibly conducted experiments. A fairly constant coefficient of variation with respect to the mean supersaturation ratio is observed in the different experiments, with a value of $44 \%$ obtained overall.

\section{Notation}

C

$C^{*}$

$C_{\mathrm{ns}}$

$D$

$f^{*}$

\section{$\Delta G^{*}$}

$J$

$J_{0}$

$k$

$M$

$R$

$r^{*}$

$S$

$T$

$t$

$\Delta T$

V

$V_{\mathrm{m}}$
Solute activity

Concentration of solute molecules

Concentration of critical nuclei

Concentration of all molecules in solution Diffusivity

Molecular attachment frequency to critical cluster

Critical nucleus Gibbs free energy

Nucleation rate

Nucleation rate pre-exponential factor

Boltzmann constant

Solvent molecular weight

Gas constant

Critical nucleus radius

Supersaturation ratio

Temperature

Time

Undercooling temperature

Volume

Solute molar volume $x$

Z

$\gamma$

$\eta$

$\kappa$

$\mu$

$\Delta \mu$

$\sigma$
Solute mole fraction

Zeldovich correction factor

Activity coefficient

Solvent viscosity

Sticking coefficient

Chemical potential

Chemical potential driving force for nucleation

Interfacial energy

\section{Subscripts, superscripts}

$\begin{array}{ll}\text { avg } & \text { Average (mean value) } \\ \text { eq } & \text { Equilibrium } \\ \text { soln } & \text { Solution }\end{array}$

\section{Acknowledgements}

M. S. gratefully acknowledges funding of the Swedish Research Council (621-2010-5391). A. R. acknowledges the support of the Science Foundation Ireland (10/IN.1/B3038).

\section{Notes and references}

1 F. L. Nordström, M. Svärd, B. Malmberg and $\AA$. C. Rasmuson, Cryst. Growth Des., 2012, 12, 4340.

2 S. Gracin, M. Uusi-Penttilä and A. C. Rasmuson, Cryst. Growth Des., 2005, 5, 1787.

3 A. F. Izmailov, A. S. Myerson and S. Arnold, J. Cryst. Growth, 1999, 196, 234.

4 F. L. Nordström and Å. C. Rasmuson, J. Chem. Eng. Data, 2006, 51, 1775.

5 Y. Sasada, T. Takano and M. Kakudo, Bull. Chem. Soc. Jpn., 1964, 37, 940.

6 N. Kubota, J. Cryst. Growth, 2008, 310, 629.

7 J. Nývlt, J. Cryst. Growth, 1968, 3-4, 377.

8 D. Kashchiev and G. M. van Rosmalen, Cryst. Res. Technol., 2003, 38, 555.

9 A. G. Walton, in Nucleation, ed. A. C. Zettlemoyer, Marcel Dekker, New York, 1969, p. 225.

10 I. V. Markov, Crystal Growth for Beginners, World Scientific, Singapore, 2003.

11 P. Bennema and O. Söhnel, J. Cryst. Growth, 1990, 102, 547.

12 A. Mersmann, J. Cryst. Growth, 1990, 102, 841.

13 A. S. Myerson and A. F. Izmailov, in Handbook of Crystal Growth, ed. D. T. J. Hurle, North-Holland, Amsterdam, 1993, vol. 1A, p. 249.

14 A. Mersmann, Chem. Eng. Res. Des., 1996, 74, 812.

15 M. Svärd and Å. C. Rasmuson, Cryst. Growth Des., 2013, 13, 1140.

16 M. Svärd, F. L. Nordström, T. Jasnobulka and Å. C. Rasmuson, Cryst. Growth Des., 2010, 10, 195.

17 M. Svärd, F. L. Nordström, E.-M. Hoffmann, B. Aziz and Å. C. Rasmuson, CrystEngComm, 2013, 15, 5020.

18 J. Nývlt, Collect. Czech. Chem. Commun., 1983, 48, 1977.

19 S. S. Kadam, H. J. M. Kramer and J. H. ter Horst, Cryst. Growth Des., 2011, 11, 1271. 
20 S. S. Kadam, S. A. Kulkarni, R. C. Ribera, A. I. Stankiewicz, J. H. ter Horst and H. J. M. Kramer, Chem. Eng. Sci., 2012, 72, 10.

21 A. A. Chernov, Modern Crystallography III-Crystal Growth, Springer-Verlag, New York, 1984.

22 F. L. Nordström and Å. C. Rasmuson, Eur. J. Pharm. Sci., 2009, 36, 330.

23 H. W. Xiang, A. Laesecke and M. L. Huber, J. Phys. Chem. Ref. Data, 2006, 35, 1597.

24 P. S. Nikam, T. R. Mahale and M. Hasan, J. Chem. Eng. Data, 1998, 43, 436.

25 J. Narayan, R. K. Wanchoo, G. K. Raina and G. A. Wani, Can. J. Chem. Eng., 1988, 66, 1021.

26 R. Moreno, A. Camacho, P. Olea, S. Canzonieri and M. Postigo, Rev. Boliv. Quim., 2001, 18, 79.
27 S. K. Hazra and C. Venkateswarlu, Chem. Petro-Chem. J., 1978, 9, 29.

28 J. G. Bleazard, T. F. Sun and A. S. Teja, Int. J. Thermophys., 1996, 17, 111.

29 D. Turnbull and J. C. Fisher, J. Chem. Phys., 1949, 17, 71.

30 J. W. Mullin and C. L. Leci, J. Cryst.Growth, 1969, 5, 75.

31 W. Pan, A. B. Kolomeisky and P. G. Vekilov, J. Chem. Phys., 2005, 122, 174905.

32 R. J. Davey, N. Blagden, S. Righini, H. Alison, M. J. Quayle and S. Fuller, Cryst. Growth Des., 2001, 1, 59.

33 S. Hamad, C. Moon, C. R. A. Catlow, A. T. Hulme and S. L. Price, J. Phys. Chem. B, 2006, 110, 3323.

34 C. S. Towler, R. J. Davey, R. W. Lancaster and C. J. Price, J. Am. Chem. Soc., 2004, 126, 13347. 